\begin{tabular}{|c|c|}
\hline 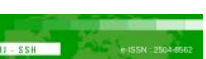 & Malaysian Journal of Social Sciences and Humanities (MJSSH) \\
\hline Malaysian Journal of & Volume 6, Issue 1, January 2021 \\
\hline (MJ-SSH) & e-ISSN : 2504-8562 \\
\hline & $\begin{array}{l}\text { Journal home page: } \\
\text { www.msocialsciences.com }\end{array}$ \\
\hline
\end{tabular}

\title{
Cabaran dalam Pelaporan Berita Tsunami: Satu Kajian Terhadap Wartawan Malaysia dan Indonesia
}

\author{
Siti Nur Ain Mustafa', Mohamad Saifudin Mohamad Saleh'1, Azman Azwan Azmawati ${ }^{1}$ \\ ${ }^{1}$ Pusat Pengajian Komunikasi, Universiti Sains Malaysia (USM) \\ Correspondence: Siti Nur Ain Binti Mustafa (sitinurain@student.usm.my)
}

\begin{abstract}
Abstrak
Bencana tsunami ini sememangnya memberikan kesan terhadap kesejahteraan ekonomi dan sosial negara. Di antara negara-negara Asia Tenggara, Indonesia dikenal pasti sebagai salah sebuah negara yang sering menghadapi bencana tsunami. Malaysia yang kedudukannya berhampiran dengan Indonesia turut menerima kesan daripada bencana tsunami yang terjadi di negara berkenaan. Kejadian bencana tsunami yang sememangnya serius ini telah mendapat pelaporan yang meluas oleh media tempatan dan antarabangsa. Bencana tsunami yang lazimnya berlaku secara tiba-tiba dan sukar untuk dijangka ini telah menyebabkan pelaporannya berbeza dengan isu-isu lain seperti jenayah, hiburan dan sebagainya. Malah, kajian-kajian lalu turut mendapati bahawa media menghadapi pelbagai cabaran dalam melaporkan berita bencana seperti tsunami yang jelas memerlukan persediaan yang rapi bagi menghasilkan penulisan yang berkualiti dan beretika. Sungguhpun kejadian tsunami adalah serius, kajian-kajian lalu terhadap pelaporan media khususnya dalam aspek cabaran wartawan dalam melaporkan isu ini adalah amat terhad. Justeru, kajian ini dijalankan dengan matlamat untuk memenuhi kelompongan kajian lepas dan seterusnya menyumbang kepada korpus penyelidikan bidang Komunikasi Bencana di Malaysia dan Indonesia. Penyelidikan ini memberikan tumpuan terhadap cabaran-cabaran yang dihadapi oleh para wartawan kedua-dua negara dalam melaporkan berita tsunami. Temu bual secara mendalam telah dilakukan bersama lapan orang wartawan dari The Star Online, Malaysia dan The Jakarta Post, Indonesia. Hasil kajian mendapati bahawa bilangan wartawan pakar isu terhad, pengetahuan terhad wartawan tentang bencana tsunami, kurang persediaan oleh bilik berita, pemotretan visual ketika bencana dan penentuan landskap berita oleh editor adalah cabaran-cabaran utama yang dihadapi oleh wartawan-wartawan di Malaysia dan Indonesia dalam melaporkan isu tsunami.
\end{abstract}

Kata kunci: Malaysia, Indonesia, tsunami, bencana, cabaran, temu bual

\section{Challenges in Tsunami News Reporting: A Study of Malaysian and Indonesian Journalists}

\begin{abstract}
The tsunami disaster has an impact on the economic and social well-being of the country. Among Southeast Asian countries, Indonesia has been identified as one of the countries most prone to tsunami disasters. Malaysia, which is located close to Indonesia, was also affected by the country's tsunami disaster. This severe tsunami disaster has received widespread reporting by local and international media. The tsunami disaster that usually occurs suddenly and is challenging to predict has made its reporting different from others like crime, entertainment, etc. Past studies have also found that the media face
\end{abstract}


various challenges in disaster news reporting, such as tsunamis that require careful preparation to produce quality and ethical writing. Although tsunamis are serious, past studies on media reporting, especially in terms of journalists' challenges in reporting this issue, are very limited. Thus, this study was conducted to meet the gaps in previous studies and further contributed to the research corpus in Disaster Communication in Malaysia and Indonesia. This research focuses on the challenges faced by journalists from both countries in reporting tsunami news. In-depth interviews were conducted with eight journalists from The Star Online, Malaysia and The Jakarta Post, Indonesia. The results of the study found that the limited number of journalists that expert with issues, limited knowledge of journalists about the tsunami, lack of newsroom preparation, visual photography during disasters and the determination of the news landscape by editors are the main challenges faced by the journalists in Malaysia and Indonesia in reporting tsunami issues.

Keywords: Malaysia, Indonesia, tsunami, disaster, challenges, interview

\section{Pengenalan}

Tsunami adalah bencana alam yang jarang berlaku, namun menghasilkan gelombang yang besar sehingga menjejaskan pelbagai kehidupan manusia dan alam sekitar (Tsunami Disaster Risk, 2016). Indonesia antara negara Asia Tenggara yang menerima impak kejadian bencana tsunami (International Tsunami Information Center, 2018). Bencana ini telah memberikan kesan kepada hampir 300,000 orang mangsa yang terjejas akibat kematian dan kehilangan tempat tinggal (Blažin et al., 2014; Lowrey et al., 2007). Tambahan pula, sumber ekonomi negara yang terlibat turut terjejas terutamanya dalam sektor pelancongan dan perikanan (Bandaralage \& Naranpanawa, 2005).

Sepanjang kejadian bencana tsunami, media menjadi sumber yang penting kepada masyarakat untuk mendapatkan maklumat berkaitan keadaan semasa bencana (Muhammad Jawed et al., 2014). Maklumat yang disampaikan oleh media tidak hanya menyentuh aspek fizikal, akan tetapi cerita yang disampaikan turut menyentuh aspek emosi kerana penyediaan liputan berita khusus yang lebih dekat menyebabkan khalayak turut merasai suasana yang berlaku di kawasan bencana (Bonati, 2015).

Tidak dinafikan, peranan wartawan dalam liputan berita bencana seperti tsunami adalah amat besar. Menurut Scanlon (2007) dan Reilly \& Atanasova (2016), peranan wartawan adalah amat penting dalam menyalurkan maklumat yang sahih mengikut tiga peringkat utama iaitu semasa pra bencana, semasa bencana dan selepas bencana kepada khalayak. Dalam pelaporan isu tsunami, media bukan sahaja berperanan dalam melaporkan tentang kesan semasa namun turut membuat dokumentari tentang sejarah tsunami yang lalu (Zamora et al., 2020). Mengambil kira peri pentingnya peranan media dan wartawan dalam pelaporan berita tsunami, kajian ini dilakukan dengan meneroka cabaran-cabaran yang dihadapi oleh wartawan-wartawan di Malaysia dan Indonesia dalam pelaporan berita tsunami di kedua-dua negara berkenaan.

\section{Sorotan Kajian Lepas}

\section{Pelaporan Berita Bencana Tsunami}

Media adalah sumber yang berkuasa dalam menyampaikan informasi tentang sesuatu peristiwa kepada khalayak (Tanikawa, 2017) terutamanya peristiwa yang berbahaya seperti kejadian bencana tsunami (Muhammad Jawed et al., 2014; Lestari et al., 2018). Media memainkan peranan sebagai ejen penyebaran amaran bencana. Menurut Zhang et al. (2014), pengurangan risiko bencana boleh berlaku apabila khalayak memperoleh maklumat tentang tindakan yang perlu dilakukan apabila mengetahui tentang bencana yang bakal berlaku. Hal ini secara tidak langsung menunjukkan bahawa media menjadi medium pendidikan dan kesedaran bencana yang amat penting. Kandungan berita yang dilaporkan oleh media adalah seperti jenis bencana, maklumat jangka masa kejadian bencana, lokasi bencana, kesan bencana, dan bantuan yang diperlukan oleh mangsa bencana (Lestari et al., 2018). 
Ndolu (2013) dalam kajiannya mendapati bahawa media mempunyai tiga peringkat pelaporan berita bencana. Pertama adalah peringkat sebelum bencana iaitu media menyalurkan informasi amaran bencana persediaan bencana, peringkat semasa bencana pula adalah tindakan yang perlu dilakukan oleh khalayak apabila berdepan dengan bencana dan peringkat selepas bencana ialah media melaporkan berita bencana yang meliputi imej kesan bencana seperti kemusnahan dan kerosakan, trauma dan bantuan (Ndolu, 2014; West \& O'Reilly, 2014). Lestari et al. (2018) menyatakan bahawa penulisan berita tsunami perlulah selari dengan keadaan semasa. Menurut mereka, semasa kejadian bencana tsunami, khalayak lebih memerlukan informasi tentang situasi kawasan bencana dan proses bantuan bencana.

Selain itu, liputan berita tsunami tidak hanya memfokuskan kepada penulisan kandungan berita sematamata, media turut menyediakan liputan berita berbentuk visual untuk meminimumkan kandungan teks. Menurut Odoemelam et al. (2015), visual dapat menterjemahkan keseluruhan kandungan teks dan dapat membangkitkan emosi pembaca apabila pembaca menghayati visual yang dipaparkan. Walau bagaimanapun, media masih terikat dengan etika dalam penyaluran maklumat bencana tsunami. Hal ini dapat dijelaskan apabila Aniqa \& Sana (2013) mendapati media kurang mengamalkan etika dalam liputan berita bencana. Etika dalam liputan berita adalah untuk memberikan keadilan antara wartawan dan sumber yang terlibat dalam liputan berita (Nur Aziemah et al., 2013).

\section{Cabaran Dalam Pelaporan Isu Tsunami}

Kesan daripada perubahan teknologi, wartawan dan media kini berada dalam tekanan untuk memenuhi keperluan khalayak untuk memperoleh maklumat (Siapera \& Veglis, 2012) terutamanya dalam berita bencana yang memerlukan penyaluran maklumat yang lebih pantas (Liu, 2010). Keperluan khalayak dilihat meningkat apabila media memperkembangkan dari segi sistem penyaluran maklumat tradisional kepada sistem elektronik. Perubahan ini dibahaskan oleh Nguyen (2013) yang menegaskan bahawa media perlu mengejar kehendak khalayak sehingga memberikan cabaran dalam proses penghasilan berita dan ruangan berita. Malah, wartawan kini perlulah menjadi seorang yang serba boleh iaitu menggalas tugasan sebagai penyampai berita dan melakukan tugasan teknikal seperti menemu bual, merakam video, memotret gambar, menulis bahan berita termasuklah berperanan dalam pasca pengeluaran (Strong \& Dow, 2011).

Selain itu, organisasi berita dilihat saling bersaing antara satu sama lain apabila terdapat pembahagian media seperti yang dibahaskan oleh Becker et al. (2000). Antaranya ialah (1) organisasi media yang besar dan (2) organisasi media yang kecil. Saiz organisasi ini menentukan kapasiti bebanan kerja seseorang wartawan dan pengamal media yang lain. Walaupun media dilihat berusaha untuk menyesuaikan diri dengan perubahan teknologi, media tetap dikritik oleh pengkritik media yang menyatakan bahawa wartawan dan agensi media tidak memenuhi harapan dan tidak melayani kehendak orang ramai. Justeru, Wilkins et al. (2012) menegaskan bahawa wartawan perlu memperkembangkan lebih banyak perancangan yang lebih baik tentang bencana alam.

Di samping itu, aspek etika organisasi media dan wartawan turut menjadi perbahasan dalam kalangan pengkritik media. Media mempunyai kecenderungan untuk menerbitkan cerita yang menarik perhatian pembaca untuk mencapai keuntungan yang telah disasarkan (Nur Aziemah et al., 2013) tanpa melihat kepada kesan daripada ketidakpekaan terhadap etika kewartawanan yang perlu dipatuhi. Kebergantungan agensi media dan wartawan terhadap etika kewartawanan perlu diperhalusi terutamanya dalam kewartawanan bencana yang melibatkan perkara-perkara sensitif tentang mangsa.

Meja berita juga dikatakan telah mewujudkan perbezaan bidang dan tema liputan berita (Magin \& Maurer, 2019). Kewujudan meja berita dan sistem pergiliran menyebabkan wartawan perlu melaporkan pelbagai berita sehingga tidak dilatih menjadi seorang wartawan pakar dalam sesuatu isu seperti bencana tsunami (Mohamad Saifudin, 2016). 


\section{Metod Kajian}

Kajian ini dijalankan dengan menggunakan reka bentuk kualitatif. Kaedah pengumpulan data yang digunakan adalah temu bual mendalam kerana kaedah ini dapat meneroka idea atau perasaan, memahami pengalaman dan pandangan responden (Shazia, 2014; Lindlof \& Taylor, 2011) iaitu wartawan. Jenis temu bual yang digunakan oleh penyelidik adalah temu bual tidak berstruktur. Menurut Shazia (2014) temu bual tidak berstruktur sesuai digunakan untuk kajian yang dijalankan dalam jangka masa yang panjang.

Temu bual dijalankan terhadap wartawan daripada akhbar dalam talian The Star Online dan The Jakarta Post untuk mencapai objektif kajian ini. Wartawan-wartawan telah dipilih dari kedua-dua organisasi media ini kerana kedua-dua akhbar ini mempunyai jumlah pembaca dalam talian yang tertinggi bagi akhbar berbahasa Inggeris di kedua-dua negara iaitu The Star Online mempunyai 1,185,000 orang pembaca (ADQRATE Built for Market, 2018) dan The Jakarta Post mempunyai 88,000 orang pembaca (The Jakarta Post, 2018). Sampel kajian ini diperoleh dengan persampelan bertujuan iaitu dengan menetapkan maklumat atau ciri yang tertentu yang perlu dimiliki oleh responden. Justeru, hanya wartawan yang memiliki sekurang-kurangnya setahun pengalaman bekerja dan responden mempunyai pengalaman dalam melaporkan isu alam sekitar khususnya bencana tsunami sahaja dipilih untuk ditemu bual dalam kajian ini (Mohamad Saifudin, 2016). Persampelan bola salju juga digunakan iaitu responden memperkenalkan rakan-rakan mereka yang berpengalaman dalam melaporkan berita tsunami untuk ditemu bual oleh pengkaji. Ianya memudahkan pengkaji kerana bilangan wartawan yang berpengalaman dalam melaporkan isu tsunami adalah terhad di kedua-dua negara.

Proses temu bual ini dilakukan terhadap lapan orang responden dari kedua-dua akhbar. Kesemua responden dilabelkan dengan kod identiti seperti EJ1, EJ2 dan sebagainya bagi menjaga kerahsiaan jawapan mereka. Analisis data temu bual dilakukan dengan menggunakan kaedah analisis tematik yang disarankan oleh Braun dan Clarke (2006) iaitu mengklasifikasikan data mengikut enam langkah seperti (a) memahami data yang diperoleh, (b) menghasilkan kod kepada data yang diperoleh, (c) mencari tematema, (d) mengkaji semula tema-tema yang dikenal pasti, (e) mentakrif dan menamakan tema-tema yang dikenal pasti, dan (f) menghasilkan laporan.

\section{Hasil Kajian}

Hasil daripada temu bual mendapati lima tema menarik yang menjurus kepada cabaran-cabaran yang dihadapi oleh wartawan-wartawan Malaysia dan Indonesia dalam melaporkan berita tsunami kepada masyarakat, seperti berikut.

\section{Bilangan Wartawan Pakar Isu Terhad}

Berdasarkan temu bual yang dijalankan, penyelidik mendapati bahawa kekurangan wartawan pakar dalam isu tsunami menjadi cabaran utama dalam pelaporan berita tsunami. Responden dari The Star Online menyatakan bahawa pengamal media di Malaysia tidak dibahagikan mengikut bidang khusus yang tetap. Keadaan ini berlaku adalah disebabkan oleh kekurangan wartawan mahir terutamanya dalam melaporkan isu seperti tsunami dikemukakan oleh salah seorang responden dari The Star Online.

\footnotetext{
"Bilangan wartawan dalam agensi media di Malaysia adalah terhad. Akibat daripada bilangan yang terhad telah mendorong wartawan untuk membuat liputan berita di luar bidang yang bukan kepakarannya. Sebagai contoh, wartawan perlu melaporkan berita politik walaupun beliau hanya mempunyai kepakaran dalam yang lain. Seseorang yang menceburi bidang kewartawanan sememangnya perlu mempunyai ilmu pengetahuan yang luas kerana mereka perlu melaporkan pelbagai jenis topik berita”. (ID EJ2)
} 
Hal yang sama turut dikemukakan oleh majoriti responden dari The Jakarta Post yang bersetuju tentang kekurangan bilangan wartawan mahir dalam melaporkan berita besar seperti tsunami. Walau bagaimanapun, sedikit berbeza dengan wartawan Malaysia, majoriti dari mereka berpendapat bahawa wartawan tetap dibahagikan mengikut kepakaran dalam bidang tugas yang diberikan.

"Wartawan di mana-mana agensi media sememangnya terhad. Oleh sebab itu, wartawan terpaksa melakukan jumlah tugasan yang melebihi dari jangkaan yang sebenarnya kerana perlu saling bersilih-ganti untuk melaporkan sesuatu kejadian agar setiap kejadian yang berlaku dapat disebarkan kepada khalayak. Walau bagaimanapun, kami di The Jakarta Post memiliki bidang tugasan utama masingmasing”. (ID EJ5)

\title{
Pengetahuan Terhad Wartawan Tentang Tsunami
}

Dapatan yang diperoleh daripada temu bual mendapati pengetahuan wartawan tentang bencana tsunami adalah rendah. Menurut responden dari The Star Online, bencana adalah sesuatu kejadian yang besar dan memerlukan pemahaman yang mendalam mengenainya. Kekurangan pengetahuan ini menyebabkan kesukaran dalam menghasilkan penulisan berita kerana wartawan perlu memahami konsep-konsep khusus tentang bencana dan menerangkan semula kepada pembaca dalam struktur ayat yang mudah difahami.

\begin{abstract}
"Tugas sebagai seorang wartawan adalah mencabar dan ia tidak semudah yang difikirkan oleh orang awam. Wartawan perlu memiliki pengetahuan am yang luas untuk menghasilkan penulisan berita yang baik. Sekiranya tidak memiliki pengetahuan yang luas, wartawan tidak akan berupaya untuk menulis dengan baik. Perkara sedemikian telah menyumbang kepada kewujudan penyunting yang memainkan peranan untuk menyemak dan membetulkan hasil penulisan wartawan sebelum ia disiarkan”. (ID EJ3)
\end{abstract}

Sejajar dengan pendapat dari responden The Star Online, responden dari The Jakarta Post turut bersetuju bahawa pengetahuan mereka dalam isu tsunami juga rendah kerana kebanyakan mereka mempunyai latar belakang pendidikan yang berbeza. Walau bagaimanapun, mereka diminta untuk menghadiri bengkel bagi mempertingkatkan pengetahuan terutamanya apabila perlu berdepan dengan bencana alam seperti tsunami yang berlaku di luar jangkaan manusia. Sekiranya pengetahuan tentang bencana tsunami kurang dititikberatkan ia akan menyumbang kepada kekurangan pelaporan berita bencana disebabkan kebanyakan wartawan di The Jakarta Post mahir dalam bidang politik.

"Sebagai wartawan, saya perlu memiliki pengetahuan yang luas. Oleh itu, menghadiri beberapa bengkel tentang cara membuat liputan mengenai keadaan yang melampau seperti konflik bersenjata dan bencana adalah penting. Melalui bengkel tersebut saya memperoleh beberapa tips seperti kelengkapan yang diperlukan ketika melaporkan bencana, gaya penulisan berita bencana dan lain-lain lagi. Di samping itu, kurangnya pemahaman mengenai isu-isu alam sekitar dan bencana telah menyumbang kepada keadaan ini (kekurangan pelaporan berita bencana) kerana kebanyakan wartawan di Indonesia biasanya pakar dalam bidang politik". (ID EJ1)

\section{Kurang Persediaan oleh Bilik Berita}

Dapatan temu bual yang dijalankan mendapati bahawa majoriti dari responden menyifatkan bilik berita The Star Online adalah berada dalam keadaan kurang bersedia untuk pelaporan bencana. Hal ini demikian kerana Malaysia adalah negara yang berada di luar garisan pusat bencana. Tahap persediaan yang rendah ini turut menyumbang kepada keresahan dalam kalangan wartawan apabila berdepan dengan bencana yang berlaku secara tiba-tiba. Ianya secara tidak langsung mempengaruhi kualiti pelaporan berita bencana tsunami mereka. 
Responden turut menegaskan bahawa liputan berita bencana tsunami juga memerlukan peralatan yang lengkap dan pematuhan terhadap Prosedur Operasi Standard (SOP). Selain itu, responden dari The Star Online turut menyatakan bahawa persediaan dalam pelaporan tsunami memerlukan struktur kewangan yang kukuh dan wartawan yang mahir dalam bidang bencana agar dapat memahami konteks berita yang seharusnya dilaporkan dengan membekalkan maklumat untuk melaporkan berita bencana yang lebih beretika agar tidak menyentuh mana-mana sensitiviti rakyat di negara ini.

\begin{abstract}
"Sejujurnya, bilik berita kami belum bersedia untukmenghadapi bencana. Sehingga kini, untuk menjadikan sesuatu bilik berita itu bersedia dalam melaporkan bencana memerlukan banyak proses dan agensi media itu perlu mempunyai sokongan kewangan yang mencukupi untuk menyediakan peralatan yang canggih sama ada untuk liputan berita dan SOP yang betul untuk keselamatan wartawan. Selain itu, setiap wartawan wajib mengetahui etika pelaporan berita. Jadi, berita nanti tidak akan menyentuh sensitiviti sebab dengan berita sahaja boleh menyebabkan pergaduhan, pertelingkahan". (ID EJ4)
\end{abstract}

Walaupun Indonesia adalah negara yang sering menghadapi bencana tsunami, namun media di Indonesia seperti The Jakarta Post masih dalam proses meningkatkan tahap persediaan bilik berita yang lebih tinggi. Majoriti responden menyatakan bahawa bilik berita mereka telah menyediakan pelan kandungan liputan berita yang bakal disiarkan dalam akhbar dalam talian kepada wartawan. Wartawan akan diberikan penerangan oleh editor sebelum berada di lapangan. Penerangan yang akan diberikan adalah tentang peralatan yang diperlukan untuk tugasan dan keselamatan diri semasa berada di kawasan kejadian. Namun begitu, menurut salah seorang responden, bilik berita The Jakarta Post memiliki kesukaran dalam penyediaan peralatan yang canggih dan wartawan mahir yang mencukupi kerana mempunyai masalah dalam kewangan. Hal ini secara tidak langsung menyebabkan kebergantungan media tersebut terhadap agensi media antarabangsa. Masalah yang dihadapi oleh wartawan The Jakarta Post untuk melaporkan kejadian bencana tsunami adalah penyediaan garis panduan yang kurang jelas oleh bilik berita dalam pelaporan bencana tsunami.

"The Jakarta Post sedar akan keperluan memiliki perancangan yang khusus untuk liputan berita bencana. Walau bagaimanapun, The Jakarta Post belum sampai pada peringkat perancangan tersebut. Akan tetapi, berdasarkan pengalaman, editor berusaha untuk mempersiapkan saya untuk tugasan melaporkan bencana dengan memberikan penerangan tentang peralatan yang perlu dibawa bersama, tempat tinggal dan cara-cara untuk kekal selamat semasa menjalankan tugas. Tambahan juga, bilik berita saya mempunyai kesukaran dari segi kewangan dan masih tidak dapat membeli peralatan tersebut”. (ID EJ5)

\title{
Pemotretan Visual Ketika Bencana
}

Bahagian ini menerangkan tentang cabaran yang dihadapi oleh wartawan ketika pemotretan visual keadaan kawasan bencana. Berdasarkan temu bual yang dilakukan terhadap responden dari The Star Online dan The Jakarta Post menunjukkan terdapat persamaan pendapat oleh majoriti dari respondenresponden tersebut. Menurut mereka, visual yang digunakan di dalam pelaporan berita tsunami perlulah menghormati privasi mangsa dan keluarga mangsa. Hal ini secara tidak langsung menjadi cabaran kepada wartawan untuk bertindak sebagai wartawan yang beretika atau sekadar untuk memenuhi permintaan pembaca.

"Etika dalam kewartawanan adalah menjaga privasi mangsa agar tidak mengaibkan mangsa pada masa akan datang. Oleh itu, sebagai wartawan, ia merupakan cabaran yang terbesar yang perlu dihadapi apabila perlu melakukan permilihan gambar yang tidak mengaibkan mangsa di samping dapat menceritakan keseluruhan keadaan kawasan bencana. Walaupun gambar yang memaparkan keadaan seperti mangsa yang terkorban mampu mendatangkan nilai emosional 
dalam kalangan pembaca, namun wartawan masih terikat dengan etika kewartawanan yang tidak boleh dilanggar sewenang-wenangnya”. (ID EJ2)

Selain itu, mereka turut menyatakan bahawa tugasan pemotretan kini telah beralih kepada tanggungjawab wartawan. Menurut salah seorang responden, wartawan kini menjalankan dua tugasan iaitu sebagai penulis dan sebagai jurugambar. Hal ini berlaku adalah berkaitan dengan perubahan teknologi yang semakin canggih dan wartawan dapat memotret gambar sendiri dengan menggunakan telefon pintar tanpa bantuan jurugambar. Walaupun ia dilihat sebagai suatu yang positif kepada wartawan kerana berupaya untuk menentukan sendiri visual yang ingin dilampirkan bersama bahan penulisan berita, akan tetapi ia adalah bebanan yang besar kepada wartawan. Wartawan perlu memberikan tumpuan kepada dua aspek iaitu penulisan dan gambar seperti yang dinyatakan oleh salah seorang responden di bawah.

"Tugas wartawan kini tidak seperti dahulu yang hanya memberi fokus kepada satu aspek sahaja iaitu aspek penulisan. Akan tetapi, kini dengan kewujudan teknologi yang canggih menyebabkan tugas wartawan menjadi berganda terutamanya wartawan akhbar. Sebagai wartawan, kami tidak boleh mengeluh dengan tugasan yang diberikan kerana kami adalah tunjang utama kepada pembaca untuk mendapatkan informasi”. (ID EJ7)

\section{Penentuan Landskap Berita oleh Editor}

Penentuan landskap penulisan berita juga menjadi cabaran kepada wartawan dalam melaporkan berita. Berdasarkan temu bual yang dilakukan terhadap responden dari The Star Online dan The Jakarta Post menunjukkan terdapat persamaan pendapat majoriti responden-responden. Menurut responden The Star Online, bahagian penulisan berita adalah satu cabaran kepada mereka kerana wartawan perlu mematuhi panduan yang diberikan oleh editor sebelum memulakan sesuatu penulisan. Perkara sedemikian berlaku adalah dipengaruhi oleh sistem pemilikan media. Walaupun wartawan bebas dalam menentukan corak penulisan berita, namun mereka masih terikat dengan agenda media tersebut.

"Wartawan mempunyai hak dalam menentukan kandungan berita, namun mereka
perlu akur dengan sidang editorial yang dijalankan apabila melibatkan
perbincangan antara wartawan dan editor. Wartawan turut tidak digalakkan untuk
menghasilkan penulisan yang tidak mengikut falsafah media itu sendiri kerana
wartawan berkhidmat kepada media tersebut dan menjadi tanggungjawab
wartawan untuk menulis berita yang menguntungkan syarikat media”. (ID EJ3)

Selain itu, kesukaran dalam penentuan kandungan penulisan berita turut dialami oleh responden dari The Jakarta Post. Menurut mereka, wartawan perlu menghasilkan penulisan berita yang memberikan impak positif kepada agensi media dan meningkatkan keuntungan agensi media tersebut. Namun, menurut salah seorang responden, sebelum tugasan diberikan kepada wartawan untuk melaporkan sesuatu peristiwa atau kejadian, suatu perbincangan akan dilaksanakan melalui aplikasi mudah alih seperti Whatsapp yang melibatkan editor dan wartawan untuk menghasilkan keputusan yang dipersetujui oleh kedua-dua pihak iaitu editor dan wartawan. Tambah mereka, terdapat dasar yang mempengaruhi proses penulisan berita. Dasar yang telah ditetapkan oleh agensi akhbar The Jakarta Post adalah cerita yang dihasilkan perlulah memaparkan konteks nasional agar dapat difahami oleh pembaca asing seperti Malaysia, Singapura dan lain-lain. Dasar ini dikatakan menjadi cabaran kepada wartawan di lapangan untuk meneruskan laporan berita kerana kandungan laporan tersebut perlu selari dengan kejadian yang berlaku.

\footnotetext{
"Sebelum sesuatu kejadian dilaporkan, wartawan dan editor akan melakukan sesi perbincangan untuk membincangkan tentang tema kandungan berita yang perlu dilaporkan. Walaupun, terdapat pelbagai idea tentang kandungan yang sepatutnya dilaporkan, namun idea tersebut perlulah mendapatkan persetujuan antara dua pihak iaitu wartawan dan editor. Akan tetapi, pada kebiasaannya editor akan mendahului dalam memberikan keputusan tentang kandungan penulisan cerita. Selain itu, wartawan turut terikat dengan dasar agensi media seperti wartawan
} 
DOI: https://doi.org/10.47405/mjssh.v6i1.584

perlu memberi fokus kepada kandungan yang bersifat nasional berbanding dalam negara sahaja supaya mudah difahami oleh pembaca antarabangsa". (ID EJ 6)

\section{Perbincangan}

Secara keseluruhannya, kajian ini mendapati bahawa terdapat lima cabaran utama yang dihadapi oleh wartawan-wartawan di Malaysia dan Indonesia dalam pelaporan berita tsunami. Pertamanya, wartawan yang bukan daripada bidang bencana dan alam sekitar turut terlibat dalam menjalankan liputan berita bencana tsunami. Ianya bukan sesuatu yang asing kerana hasil kajian lalu oleh Nur Aziemah et al. (2013) dan Mohamad Saifudin, Heinrichs dan Nik Norma (2018) turut mendapati bahawa kebanyakan wartawan yang terdapat dalam organisasi media di Malaysia adalah terdiri daripada latar belakang pendidikan yang pelbagai dan sesetengahnya mempunyai latar belakang pendidikan dalam bidang komunikasi dan kewartawanan. Implikasinya, wartawan yang berlainan bidang ini cenderung mempunyai perspektif sendiri apabila melaporkan berita bencana (McCluskey, 2008). Malah, sesetengah isu alam sekitar atau bencana juga berkait dengan elemen Islam dalam akhbar tempatan di Malaysia yang turut menyulitkan wartawan yang tidak mempunyai latar belakang pendidikan dalam bidang berkenaan (Mohamad Saifudin \& Nik Norma, 2019).

Selain itu, cabaran yang dihadapi oleh wartawan bukan dari bidang bencana atau alam sekitar adalah lebih kepada risiko keciciran maklumat dan fakta dalam penulisan berita bencana seperti tsunami disebabkan oleh pengetahuan yang terhad tentang isu berkenaan. Pengetahuan yang khusus dalam bidang bencana adalah penting kerana wartawan yang tidak memahami konsep sebenar pelaporan berita bencana akan menimbulkan kesukaran dalam penulisan berita terutamanya yang melibatkan berita kecemasan (Lowrey et al., 2007). Pemahaman seseorang wartawan akan membantu mereka untuk menghasilkan pelaporan yang baik. Walau bagaimanapun, pengetahuan tentang sesuatu bidang juga dapat diperoleh daripada pengalaman wartawan dalam melaporkan sesuatu kejadian semasa mereka bekerja (Perrin \& Dow, 2009). Pengalaman yang diperoleh wartawan menjadikan mereka lebih menyedari apa yang mereka lakukan semasa proses penulisan (Perrin \& Dow, 2009) seperti bencana tsunami.

Hasil kajian ini turut mendapati bahawa persediaan dari sudut dalaman organisasi media turut menjadi cabaran oleh wartawan-wartawan dalam pelaporan berita tsunami. Kewartawanan bencana adalah proses pengumpulan dan penyampaian berita berkaitan kejadian semula jadi atau manusia yang telah terjadi, sedang terjadi atau mungkin berlaku pada masa akan datang (Houston, Reed \& Schraedley, 2019). Kewartawanan bencana ini lazimnya melaporkan bahagian sebelum, semasa dan selepas bencana (Houston, Pfefferbaum \& Rosenholtz, 2012). Organisasi media diakui mempunyai persediaan dari sudut masa kerana media beroperasi selama 24 jam (Crisis Emergency Risk Communication, 2014). Wartawan dan organisasi media juga sering melaporkan kejadian bencana sebagai berita terkini (breaking news) (Ali \& Jiang, 2020). Walau bagaimanapun, berdasarkan dapatan temu bual, wartawan dari Malaysia dan Indonesia menyatakan bahawa persediaan agensi media di kedua-dua buah negara tersebut masih berada pada paras yang kurang memuaskan iaitu wartawan perlu melaksanakan tugas yang pelbagai termasuklah tugas-tugas teknikal (Strong \& Norman, 2017). Hal ini telah menyebabkan pelaporan berita bencana tsunami lebih mencabar berbanding berita-berita lain.

Seterusnya, wartawan juga menghadapi cabaran dalam melaporkan kejadian bencana disebabkan oleh keperluan kemahiran yang pelbagai yang meliputi kemahiran sebagai penulis dan jurugambar. Situasi ini berlaku disebabkan oleh perkembangan teknologi yang berlaku secara mendadak yang mempengaruhi peralihan tugasan wartawan tradisional kepada wartawan digital (Domingo et al., 2011; Dickinson, 2008). Malahan, dalam aspek pemotretan visual ketika bencana juga didapati menjadi cabaran kepada wartawan. Hal ini kerana, visual adalah alat yang berkesan dalam komunikasi kerana ia bukan sahaja mewakili fakta, gambar juga mempunyai kemampuan untuk berinteraksi dengan pembaca yang berkaitan sehingga ke peringkat emosional (Shields, 2014). Walaupun visual memainkan peranan yang besar dalam liputan berita bencana, usaha dalam pemotretan visual adalah sesuatu yang mencabar bagi seseorang wartawan yang kurang mahir dalam mengambil gambar. Pengaruh visual dalam pelaporan berita turut mewujudkan tanggungjawab etika dalam bidang kewartawanan supaya visual berita yang disalurkan kepada khalayak adalah benar dan beretika (Shields, 2014; Maenpaa, 2014). Berdasarkan 
temu bual, wartawan menyatakan bahawa mereka perlu mengaplikasikan etika dalam pemotretan visual tsunami untuk menghormati privasi mangsa dan mengelakkan daripada penggunaan visual yang menyentuh sensitiviti mana-mana pihak.

Selain itu, hasil daripada penyelidikan ini turut menemui cabaran wartawan dari agensi media di Malaysia dan Indonesia yang menghadapi kesukaran dalam menentukan kandungan berita tsunami yang dipengaruhi oleh beberapa faktor. Pertamanya adalah dipengaruhi oleh aspek pemilikan akhbar (Thurman, 2011) dan keduanya adalah kehendak pembaca (Conboy, 2004; Hudson dan Rowlands 2007). Di samping itu, penghasilan berita bencana tsunami juga adalah dipengaruhi oleh tahap pengalaman seseorang wartawan (Mott 2006). Memiliki pengalaman yang tinggi membantu wartawan dalam pemilihan informasi yang tepat sebelum ia dijadikan sebagai berita (Fahmy, 2008). Tambahan pula, pengalaman akan menjadikan wartawan memiliki perancangan yang lebih efisen iaitu daripada proses pemilihan berita, sumber yang akan ditemu bual, dan bahan yang perlu dan tidak perlu dimasukkan di dalam berita seperti visual atau lain-lain multimedia (Fisher, 2018). Tambahan lagi, hirarki dalam bilik berita juga mempengaruhi penentuan landskap berita bencana tsunami (Reese 2019). Penonjolan editor dapat dilihat dalam aspek ini. Walaupun wartawan diberikan peluang untuk mengemukakan idea utama bagi sesuatu liputan berita, namun idea tersebut perlu mendapat persetujuan daripada editor (Mellado, 2011).

\section{Kesimpulan}

Wartawan adalah individu yang bertanggungjawab dalam menghasilkan dan melaporkan berita kepada khalayak. Namun begitu, dalam pelaporan isu bencana seperti tsunami, terdapat pelbagai cabaran yang dihadapi oleh wartawan di Malaysia dan Indonesia. Cabaran-cabaran yang dikemukakan ini boleh diatasi oleh organisasi media dengan menambah baik dan memantapkan operasi di bilik berita dan memberikan latihan yang baik kepada para wartawan. Perkara yang terpenting adalah organisasi media dan wartawan perlulah memastikan pelaporan yang benar dan telus dalam isu bencana seperti tsunami. Malah, berita tsunami tidak sewajarnya disensasikan. Dengan cara sebegini, organisasi media boleh mengelakkan kritikan dari masyarakat yang boleh menjejaskan reputasi dan kredibiliti wartawan dan mereka (Faridah, 2010).

Secara konklusinya, kajian ini telah memberikan gambaran yang jelas tentang cabaran-cabaran yang dihadapi oleh para wartawan dalam pelaporan berita bencana tsunami. Kajian akan datang diharap dapat meneroka corak pelaporan berita tsunami dalam akhbar antara kedua-dua negara dan membuat perbandingan. Malah, kajian akan datang juga boleh mengkaji media negara kejiranan seperti Thailand yang turut terjejas disebabkan oleh bencana tsunami. Penerokaan terhadap pandangan masyarakat tentang kesan pelaporan berita tsunami kepada pengetahuan mereka juga boleh dilakukan oleh pengkajipengkaji pada masa akan datang.

\section{Rujukan}

Ali, R., Jiang, S. (2020). Breaking news of disasters: How Stuff.co.nz and NZHerald.co.nz used Facebook and Twitter in the 2016 Kaikoura earthquake coverage in New Zealand. Cogent Social Sciences, 6(1), 1-17.

Aniqa, A., Sana, M. (2013). Photojournalism and disaster: Case study of visual coverage of flood 2010 in national newspapers. Academic Journal of Interdisciplinary Studies, 2(9), 168-176.

Bandaralage, J., Naranpanawa, A. (2007). The economic effects of the Asian Tsunami on the "tear drop in the Indian Ocean": A general equilibrium analysis. South Asia Economic Journal, 8(1), 1-27.

Becker, L., Lowrey, W., Claussen, D., Anderson, W. (2000). Why does the beat go on?, Newspaper Research Journal, 21(4), 2-16.

Blažin, N., Gavrilov, M, B., Markovic, S. (2014). The tsunami of 26th December 2004: the impact on tourism trends in Southeast Asia. WIT Transactions on Ecology and The Environment, 181. 175185. 
Bonati, S. (2015). Multiscalar narrative of a disaster: From media amplification of western participation in Asia Tsunami. Journal of Current Culture Research, 7, 496-511.

Braun, V., Clake, V. (2006). Using thematic analysis in psychology. Qualitative Research in Psychology, 3(2), 77-101

Conboy, M. (2004). Journalism: A critical history. London: Sage Publication.

Domingo, D. (2011). Managing audience participation: Participatory journalism. Guardian Open Gates at Online Newspapers, 76-95.

Fahmy, S. (2008). How online journalists rank importance of news skills. Newspaper Research Journal, 29(2), 23-39.

Faridah, I. (2010). Press freedom and ethics with accountability: Premises and constraints. International Conference on Free and Responsible Journalism, 27-31

Fisher, C. (2018). News sources and journalist/sources interaction. Oxford Research Encyclopedia of Communication, 1-18.

Hudson, G., Rowland, S. (2007). The Broadcast Journalism. Handbook, Pearson Longman.

Houston, J. B., Pfefferbaum, B. (2012). Disaster news: Framing and frame changing in coverage of major U.S. natural disasters, 2000-2010. Journalism \& Mass Communication Quarterly, 89(4), $606-623$.

Houston, J, B., Reed, K., Schraedey, M., Worley, M, E. (2019). Disaster journalism: Fostering citizen and community disaster mitigation, preparedness, response, recovery and resilience across the disaster cycle. Disaster, 43(6), 1-20.

Lestari, P., Ramadhaniyanto, B., Wardyaningrum, D. (2018). Pemberitaan di media online untuk pengurangan risiko bencana Gunung Sinabung. Jurnal Kajian Komunikasi, 6(1), 106-120.

Liu, D. (2010). A comparative look at the coverage of the Sichuan earthquake. Thesis Dissertation, Iowa State University, Ames, Iowa, 1-77.

Lowrey, W., Evans, W., Gower, K, K., Robinson, J, A., Ginter, P, M. (2007). Effective media communication of disasters: Pressing problems and recommendations. BMC Public Health, 7(97), $1-8$.

Mäenpää, J. (2014). Rethinking photojournalism: The changing work practices and professionalism of photojournalists in the digital age, Nordicom Review, 35,91-104.

Magin, M., Maurer, P. (2019). Beat journalism and reporting. Oxford Research Encylopedia of Communicatio, 1-22.

McCluskey, M. (2008). Reporterbeat and content differences in environmental stories. Journalism \& Mass Communication Quarterly, 85(1), 83-98.

Mellado, C. (2011). Examining professional and academic culture in Chilean journalism and mass communication education. Journalism Studies, 12(3), 375-391.

Mohamad Saifudin, M. S. (2016). Environmental communication among the media and environmental non-governmental organisations (ENGOs) in Malaysia: A roller coaster ride? Tesis PhD Leuphana University of Lüneburg, Jerman.

Mohamad Saifudin, M. S., Heinrichs, H., \& Nik Norma, N. H. (2018) The struggles of Malaysian media and environmental non-governmental organisations (ENGOs) in communicating the environment within semi-democratic nation. The Journal of International Communication, 24(1), 55-75.

Mohamad Saifudin, M. S., \& Nik Norma, N. H. (2019). Analysing Islamic elements in environmental news reporting in Malaysia. Media Watch, 10(1), 54-67.

Mott, F. L. (2006). What's the news? In Adams, G. S., Clark, R. P. Journalism the democtratic craft. Oxford: Oxford University Press.

Muhammad Jawed, I., Fatima. M. A., Muhammad Bilal, K., Sadaf, S. (2014). Analysis of Role Media in Disaster Reporting in Pakistan. European Scientific Journal, 1, 570-575.

Nguyen, A. (2013). Journalism: New Challenges. Chapter 9: Online news audiens: The Challenges of web metrics. Bournemouth University Centre for Journalism \& Communication Research, 144162.

Nur Aziemah, M, A., Ismail, S., Illias, M, S. (2013). The knowledge, attitude and acceptance of journalism ethics among journalism. International Conference on Democratisation in Southeast Asia (ICDeSA 2019), 62(14), 66-69.

Odoemelam, C. C, U. V. (2015). Visual news patterns and the Boko Haram Insurgence in Nigerian Newspaper. Journal of New Media and Mass Communication, 31-39. 
Perrin, D., Dow, M. E. (2009). Capturing translation process to access metalinguistic awareness. Journal of Across Language and Cultures, 10(2), 275-288.

Reilly, P., Atanasova, D. (2016). A report on the role of the media in the information flow that emerge during crisis situations. SP Technical Research Institute of Sweden, 1-41.

Reese, S. (2019). Hierarchy influences. The International Encyclopedia of Journalism Studies, 1-5.

Scanlon, J. (2007). Research about the mass media and disaster: Never (Well hardly ever), 1-48. Diambil dari: https://training.fema.gov/emiweb/downloads/scanlonjournalism.pdf

Siapera, E., Veglis, A. (2012). Introduction: The evolution of online journalism. The Handbook of Global Online Journalism, 1-17.

Shazia, J. (2014). Qualitative research method-interviewing and observation. J Basic Clin Pharm, 5(4), 87-88.

Shields, M, L. (2014). Ethics in photojournalism: Authenticity and sensitivity in coverage of tragic event. Communication Theses, Georgia State University, 1-75.

Strong, C, R., Norman, Z. (2016). Natural disaster strategic communication: Drone, data and backpack journalism trends. Conference: Eighth International Forum on Public Relations and Advertising Eighth International Forum. Wellington. 1-16.

Tanikawa, M. (2017). What is news? What is the newspaper? The physical, functional, and stylistic transformation of print newspapers, 1988-2013. Internation Journal of Communication, 11, 35193540 .

Thurman, N. (2011). Making 'the daily me': Technology, economic and habit in the mainstream assimilation of personalize news, Journalism, 12(4), 395-415.

Wilkins L, Steffens M, Thorson E et al. (2012) Reporting Disaster on Deadline: A Handbook for Students and Professionals. New York: Routledge.

Zamora, N., Gubler, A., Orellana, V., León, J., Urrutia, A., Carvajal, M., Cisternas, M., Catalán, P., Winckler, P., Cienfuegos, R., Karich, C., Vogel, S., Galaz, J., Pereira, S., \& Bertin, C. (2020). The 1730 great metropolitan chile earthquake and tsunami commemoration: Joint efforts to increase the country's awareness. Geosciences, 10, 1-15.

Zhang, N., Huang, H., Su, B., Zhao, J., Zhang, B. (2014). Information dissemination analysis of different media towards the application for disaster pre-warning. Plos One, 9(5), 1-12. 